\title{
Optical Diagnostic Equipment for Research on Critical Processes in Spark-Ignition Engines
}

\author{
Final Report \\ Department of Energy University Research Instrumentation Program \\ Contract No: DE-FG02-95TE00065
}

Simone Hochgreb

Sandia National Laboratories

(at Massachusetts Institute of Technology

until 01/31/99)
RECEIVEO

JAN $\cap 320020$

OSTI

August 8, 1999

Simone Hochgreb

Sandia National Labs

MS 9053

PO Box 969

Livermore, CA 94550

Email: shochgr@ca.sandia.gov

Phone: (925)294-4724 


\section{DISCLAIMER}

This report was prepared as an account of work sponsored by an agency of the United States Government. Neither the United States Government nor any agency thereof, nor any of their employees, make any warranty, express or implied, or assumes any legal liability or responsibility for the accuracy, completeness, or usefulness of any information, apparatus, product, or process disclosed, or represents that its use would not infringe privately owned rights. Reference herein to any specific commercial product, process, or service by trade name, trademark, manufacturer, or otherwise does not necessarily constitute or imply its endorsement, recommendation, or favoring by the United States Government or any agency thereof. The views and opinions of authors expressed herein do not necessarily state or reflect those of the United States Government or any agency thereof. 


\section{DISCLAIMER}

Portions of this document may be illegible in electronic image products. Images are produced from the best available original document. 


\section{Introduction}

The equipment requested under grant Contract No: DE-FG02-95TE00065 was used in several projects investigating the behavior of fuel in spark-ignition engines, as described below. It has been a crucial piece of our efforts in understanding how new direct-injected engine sprays behave, as well as a key part in the determination of how liquid fuel enters the engine during port-fuel injection.

The availability of the instrumentation made it possible for us to submit a successful proposal to DOE as well as industrial sponsors on direct-injected engine operation, which has resulted in a number of recent publications, as detailed below.

\section{Research Projects}

\section{Investigation of the effects of fuel volatility on the behavior of high-pressure swirl spravs}

Support: DOE grant DE-AC04-94AL85000 and the MIT Engine and Fuels Research Consortium (several industrial sponsors)

Objectives: To study the effect of fuel volatility in direct-injection stratified engines. Specifically, the study used laser induced fluorescence (LIF) imaging with dopants of varying volatility, as well as phase-doppler particle analysis (PDPA) and laser elastic scatter to determine how high-pressure swirling sprays behave at different operating conditions with respect to ambient pressure and fuel temperature.

\section{Conclusions:}

The spray behavior is significantly affected by the operating conditions as well as fuel volatility. The following conclusions were drawn from the imaging and phase-doppler analysis measurements:

1. As conditions exceeded the boiling point of the fluid, rapid vaporization of light ends of the fuel (flash boiling) was observed, resulting in a vapor core along the axis of the spray. This vapor core penetrated axially more quickly than the bulk of the droplets.

2. Flash boiling significantly changes the structure of the spray, leading to a more compact spray, different from the spray obtained under cold conditions. Significant stratification of the boiling point components takes place, with the lighter components at the center and heavier components along the spray sheet.

3. The penetration of the main portion of the spray is faster for higher fuel temperatures, lower ambient density, early-injection timings, and higher volatility components of the fuel.

4. The spray width is maximized for lower fuel temperatures, low ambient density, BDC injection timing, and low volatility fuel components.

5. Intake flows were shown to affect the spray distribution for early to mid time injection $\left(90^{\circ} \mathrm{ATDCI}\right.$ to $\left.\mathrm{BDC}\right)$. The sprays injected at this timing also exhibited 
greater effects due to flash boiling due to decreased ambient pressure (intake restrictions) and increased ambient temperature (higher fraction of residual gas)

6. The droplet Sauter mean diameter (SMD) of the spray was found to decrease substantially with increasing fuel temperature and decreasing ambient density. Under conditions with a low potential for vaporization, the observed trends agree with published correlations for pressure-swirl atomizers.

7. Under conditions with a high potential for vaporization (low pressure, high temperature or volatile fuels), an additional droplet size reduction mechanism was observed, which was associated with flash boiling or evaporation of the volatile components in the fuel. The predicted droplet diameter decrease due to the observed increase in initial cone angle is sufficient to explain this volatility-induced mechanism, suggesting that the vapor production increases the cone angle of the liquid sheet before breakup.

A computational study was also performed to understand the physics leading to the changes observed in the imaging and PDPA analysis, as well as to identify shortcomings in existing models for engine sprays. Eight cases were run with changes to the inputs representing aspects of the flash-boiling spray. First, the mean droplet diameter was decreased to follow the PDPA measurements at low pressure and high temperature. Second, rapid vapor production was added. Third, the initial cone angle was increased to match the imaging experiments. The following results were obtained.

1. The primary effect of the decreased droplet size was a decreased axial and radial penetration. The decreased axial penetration of the pre-spray agrees with the imaging experiments when droplet size is decreased due to increased temperature. The decreased width is consistent with imaging experiments of sprays with increasing temperature before the onset of flash boiling.

2. Vapor addition produced a column of vapor that runs down the axis of the spray increasing the gas velocity along the centerline. The presence of a column of vapor agrees with the hot spray images of the acetone-doped fuel mixtures. When the vapor addition was immediately from the injector, rather than gradually within the spray, the gas velocities were increased sufficiently to cause increased penetration of the spray. This produced an elongated, columnar spray, which resembles the downstream structure of the flash-boiling sprays.

3. With the increased cone angle, even decreasing the SMD to $8 \mu \mathrm{m}$ was insufficient to cause the contraction in the spray necessary to limit its radial penetration. The sprays, therefore, were too wide, and the axial penetration was too small compared to the expected experimental values. Therefore, since the increase in outer initial cone angle and the decrease in mean droplet size are known from the experiments, a high degree of vapor generation is required to increase the axial penetration and elongate the spray. Since these wide cone angles only occur at high levels of superheat, substantial vapor production is likely to be occurring in the experiments.

\section{Impact:}

The combination of experiments and modeling reveals the non-intuitive conclusions regarding the role of spray droplet diameters on the evaporation rates: First, the largeSMD spray, evaporates much more quickly than the small-SMD spray, as a result of its 
higher velocities and penetration into warmer, fuel-lean regions [check!]. Second, the SMD of the sprays decreased with evaporation, rather than increasing due to preferential evaporation of the smaller droplets, apparently because the smaller droplets are entrained into the interior of the spray where vapor concentrations are high and temperatures low, thus limiting their evaporation.

The message to designers is therefore that the manner in which the spray interacts with the surrounding gas flows may be more important than the original spray characteristics. A spray pattern that directs high momentum, moderately-sized droplets into the wider gas stream (without impinging on walls) may be more effective in producing rapid vaporization than a highly atomized spray. Furthermore, the interaction between the droplets and the flow created by the spray itself suggests that modulating the spray flow (perhaps by increasing the velocity of the jet during injection) may have advantages in minimizing wall wetting while enhancing vaporization.

Publications: [1-5]

\section{Liquid fuel visualization near the intake valve using laser-induced fluorescence}

Support: MIT Engine and Fuels Research Consortium (several industrial sponsors)

Objectives: To study the process of liquid fuel transport into the cylinder of a portinjected spark-ignited engine, using laser induced fluorescence (LIF) and phase doppler particle analysis (PDPA) during cold start and steady state operation

\section{Conclusions:}

1. Four fuel transport mechanisms (first forward flow, atomization, injection contribution, high speed intake flow transport and fuel film squeezing) were identified and quantified based on the LIF and PDPA studies.

2. Increased film atomization occurs in areas which feature high magnitudes of intake air flow velocity due to the shape of the intake port. In areas where flow recirculation occurs, liquid fuel film flow is more prominent, resulting in liquid fuel droplet production due to fuel film squeezing.

3. With closed valve injection, these film driven transport mechanisms are observed for longer during warm-up than with open valve injection due to more significant wall film development. With open valve injection, the dominant liquid fuel transport mechanism is direct transport of liquid fuel from the injector into the cylinder due to the injection contribution.

4. With open valve injection a steady decrease of liquid fuel flow into the cylinder occurs during engine warm-up. With closed valve injection a flow maximum at about 15 seconds after engine start-up (with a particular fueling strategy) was observed due to significant wall film build-up in the intake port. With open valve injection most liquid fuel enters the cylinder through the front end of the intake valve where it is carried by interaction with the intake airflow.

5. Efforts to quantitatively correlate integrated PLIF intensity images with the PDPA measurements had only limited success, as the liquid fuel pattern is three 
dimensional. PLIF images are very essential, however, for the interpretation of the PDPA data.

\section{Impact:}

These studies formed a comprehensive picture of the mechanism of transport of liquid fuel during cold start operation. Liquid fuel presence is the main source of unburned hydrocarbons during cold start. Therefore, understanding the process by which it enters the cylinder and escapes vaporization is essential to understanding hydorcarbon emissions mechanisms.

Publications: [6-9]

\section{Publications}

The following publications have resulted from the use of the equipment acquired with the current grant:

1. B. A. VanDerWege and S. Hochgreb, Effects of Fuel Volatility and Operating Conditions on Fuel Sprays in DISI Engines: (1) Imaging, in preparation, submitted SAE 00P-257a, 1999.

2. B. A. VanDerWege and S. Hochgreb, Effects of Fuel Volatility and Operating Conditions on Fuel Sprays in DISI Engines: (2) PDPA studies, in preparation, submitted SAE 00P-257b, 1999.

3. B. A. VanDerWege and S. Hochgreb, Numerical Modeling of Fuel Sprays in DISI Engines under Early-Injection Operating Conditions, in preparation, submitted SAE 00P-258, 1999.

4. B. A. VanDerWege and S. Hochgreb, The Effect of volatility on sprays from HighPressure Swirl Injectors, Twenty-Seventh Symposium (International) on Combustion, The Combustion Institute, 1998, pp. 1865-1871.

5. M. H. Shelby, B. A. VanDerWege and S. Hochgreb, Early Spray Development in Gasoline Direct-Injected Spark Ignition Engines, SAE Paper 980160 (1998).

6. M. Dawson and S. Hochgreb, Liquid Fuel Visualization Using Laser-Induced Fluorescence During Cold Start, SAE Paper 982466 (1998).

7. Meyer, R. and Heywood, J. B., Evaporation of in-cylinder liquid fuel droplets in an SI engine: A diagnostic-based modeling study, SAE Paper 1999-01-0567 (1999).

8. Meyer, R. and Heywood, J. B., Effect of engine and fuel variables on liquid fuel transport into the cylinder in port-injected SI engines, SAE Paper 1999-01-0563 (1999).

9. R. Meyer, E. Yilmaz, J. B. Heywood, Liquid fuel flow in the vicinity of the intake valve of a port-injected SI engine, SAE Paper 982471 (1998). 